\title{
MOMENTOS \\ CRÍTICOS: \\ FORMAÇÃO \\ INFORMADA \\ NO ENSINO- \\ APRENDIZAGEM \\ DE PLA EM CONTEXTO \\ DE MIGRAÇÃO \\ FORÇADA
}

MOMENTOS CRÍTICOS: FORMACIÓN INFORMADA EN LA ENSEÑANZA-APRENDIZAJE DE PLA EN CONTEXTO DE MIGRACIÓN FORZADA

CRITICAL MOMENTS: INFORMED FORMATION IN PAL LEARNING AND TEACHING IN THE CONTEXT OF FORCED MIGRATION

Maria Gabriel

Universidade Federal do Paraná

Jeniffer Imaregna Alcantara de Albuquerque Universidade Tecnológica Federal do Paraná

\footnotetext{
Doutoranda em Letras pela Universidade Federal do Paraná - UFPR. Atualmente, é professora e uma das coordenadoras do projeto de extensão Português Brasileiro para Migração Humanitária - PBMIH da UFPR. E-mail: mgabriel.ufpr@gmail.com.

Professora na Universidade Tecnológica Federal do Paraná (UTFPR) nas áreas de psicolinguística, desenvolvimento linguístico de Línguas Adicionais (Português e Inglês) e formação de professores. E-mail:
} jeniffer.albuquerque@gmail.com. 
RESUMO: Este trabalho se insere na esteira de reflexões sobre o processo de ensino-aprendizagem de Português como Língua Adicional (PLA) no contexto de refúgio e/ou migração forçada. Como objetivo, pretendemos refletir sobre a construção da identidade de professores de PLA no ensino de comunidades migrantes, por meio de incidentes/momentos críticos nos processos de negociação entre professores e alunos estrangeiros. Para tanto, nos baseamos na concepção de momentos/incidentes críticos descritos por Pennycook (2004) e Farrell (2008) para analisar entrevistas orais realizadas com professores do projeto PBMIH (Português Brasileiro para Migração Humanitária). Entre os resultados, apontamos que as narrativas construídas pelos professores estão intimamente ligadas com a experiência ou inexperiência com o ensino de Línguas Adicionais e, de modo geral, os momentos críticos ocorridos em sala de aula (presentes em seus relatos ao longo das entrevistas) geraram mudanças no planejamento do curso que estavam ministrando.

PALAVRAS-CHAVE: Português como Língua Adicional. Momentos críticos. PBMIH.

RESUMEN: Este trabajo forma parte de las reflexiones sobre el proceso de enseñanza y aprendizaje de Portugués como Lengua Adicional (PLA) en el contexto de refugio y/o migración forzada. Como objetivo, pretendemos reflexionar sobre la construcción de la identidad de los profesores de PLA en la enseñanza en comunidades migrantes, a través de incidentes/momentos críticos en los procesos de negociación entre profesores y alumnos extranjeros. Para eso, nos basamos en la concepción de momentos/incidentes críticos descriptos por Pennycook (2004) y Farrel (2008) para analizar entrevistas orales realizadas con profesores del proyecto PBMIH (Portugués Brasileño para la Migración Humanitaria). Entre los resultados, señalamos que las narrativas construidas por los profesores están estrechamente vinculadas con las experiencias o inexperiencias con la enseñanza de Lenguas Adicionales y, de modo general, los momentos críticos ocurridos en clase (presentes en sus relatos a lo largo de las entrevistas) generaron cambios en la planificación del curso que enseñaban.

PALABRAS CLAVE: Portugués como Lengua Adicional. Momentos críticos. PBMIH.

ABSTRACT: This work is embedded in both learning and teaching processes of Portuguese as an Additional Language (PAL) in the context of refuge and/or forced migration. As for the work's goals, we intend to reflect upon the construction of identity issues of PAL teachers, by taking into account critical incidents/moments in the negotiation processes between teachers and foreign students. Hence, we support our reflections in the concept of critical moments/incidents as described by Pennycook (2004) and Farrell (2008) in order to analyze oral interviews conducted with PBMIH (Brazilian Portuguese for Humanitarian Migration) teachers. Results pointed out to the fact that the constructed narratives of the teachers are closely connected to their experience or lack of it in Additional Languages' teaching and, in general, the critical moments which happened during the classes (those who were reported in their interviews) caused changes in the course's plan.

KEYWORDS: Portuguese as an Additional Language. Critical Moments. PBMIH.

\section{INTRODUÇÃO}

Embora não tão recentes, os estudos que se debruçam sobre Português como Língua Adicional (PLA) ${ }^{1}$ começam a surgir na década de 70 e passam por um período de efervescência na década de 80 (ALMEIDA FILHO, 2012). Nos anos seguintes, no mesmo período que o ensino-aprendizagem e as pesquisas de outras Línguas Adicionais, os estudos em PLA foram se constituindo a partir das demandas pedagógico-políticas, provindas de situações vivenciadas no chão da sala de aula e de mudanças linguístico-políticas no status do português. Como discutiremos, as demandas flutuam ao longo dos anos em relação ao ensino para fins de turismo, trabalho, estudo e, mais recentemente, como aquisição de bens simbólicos e materiais com o grande fluxo de estrangeiros provindos de processos de migração não voluntária para o Brasil.

A partir do cenário acima exposto, a recente agenda de pesquisas na área de PLA no Brasil, ao menos desde a chegada de migrantes com as mais variadas situações de visto, tem se voltado para o processo de ensino-aprendizagem de PLA para comunidades que migraram para o país devido a desastres naturais, guerras civis, crises econômicas e perseguição política. Ao final de 2016, o Brasil ${ }^{1}$ É importante salientar a existência de outras siglas associadas à área. Para uma discussão mais aprofundada sobre as nomenclaturas associadas ao ensino de
português para não nativos, ver Almeida Filho e Cunha (2007). 
tinha mais de 9,5 mil refugiados (número que representa apenas as solicitações de pedido de refúgio deferidas) de 82 nacionalidades. As normas para solicitação de refúgio ${ }^{2}$ no país foram estabelecidas pela Lei 9474 de 1997, a Lei de Refúgio Brasileira, que foi inspirada na Convenção Internacional para Refugiados, de 1951, e na Declaração de Cartagena, de 1984. Foi essa legislação que criou o Comitê Nacional para Refugiados (CONARE), órgão colegiado vinculado ao Ministério da Justiça a quem cabe avaliar a concessão do refúgio no Brasil e articular políticas para que os direitos dos refugiados sejam efetivados.

Como parte do ciclo de chegada desses migrantes ao Brasil, surge a necessidade de criação de cursos emergenciais de português e de metodologias e práticas que acolham o aprendiz, inserindo-o na dinâmica social-local, no mercado de trabalho e em situações de estudos formal (volta aos bancos escolares ou reingresso no ensino superior). Com isso, pontua-se o exemplo de projetos como o Português Brasileiro para Migração Humanitária - PBMIH da Universidade Federal do Paraná (UFPR), que possui um grande número de professores bolsistas e voluntários e contribui nacionalmente com a implementação de cursos de PLA no contexto de migração e refúgio.

A partir desse panorama, este trabalho tem por objetivo principal refletir sobre a construção da identidade de professores de PLA no ensino de comunidades migrantes, por meio de incidentes/momentos críticos nos processos de negociação entre professores e alunos. Para tanto, partimos de um breve histórico da formação do PBMIH, descrevendo sua estrutura organizacional, sua configuração atual e suas práticas. Após, elencamos as concepções teóricas que nortearam os procedimentos metodológicos e as análises propostas nesse trabalho.

\section{O PROJETO DE EXTENSÃO UNIVERSITÁRIA PBMIH}

Desde 2013, o projeto de extensão Português Brasileiro para Migração Humanitária oferece aulas de português ${ }^{3}$ para migrantes portadores de visto de acolhida humanitária, refúgio, apátridas e/ou migrantes em vulnerabilidade social, moradores de Curitiba e região metropolitana. O objetivo principal do projeto é promover o acolhimento desses sujeitos na cidade de Curitiba, na UFPR e no Português Brasileiro (PB). Para esses migrantes, a língua portuguesa nem sempre é uma escolha, mas ao chegarem ao Brasil, ela se torna um instrumento indispensável ao processo de (re)construção identitária.

Atualmente, o PBMIH é parte integrante do programa de extensão Política Migratória e a Universidade Brasileira - PMUB. Tal programa possui um caráter nitidamente interdisciplinar e articula as atividades de extensão universitária com organizações da sociedade civil, instâncias e órgãos públicos e promove um diálogo permanente entre diferentes grupos da comunidade. Ademais, o PMUB encontra-se sob a tutela da Cátedra Sérgio Vieira de Mello em decorrência do Termo de Parceria firmado com o Alto Comissariado das Nações Unidas para Refugiados - ACNUR. As atividades do PMUB iniciaram-se em 2013 com ações implementadas pelo PBMIH, mas, nos últimos anos, o programa expandiu seu campo de atuação e as áreas que, atualmente, compõem o programa são: Letras, Direito, Informática, História, Psicologia, Sociologia e Medicina. A Figura 1 ilustra a estrutura organizacional atual do programa:

\footnotetext{
${ }^{2}$ Cabe mencionar que as estatísticas, em grande maioria, geradas sobre o número de migrantes contemplam, em geral, apenas o número de pedidos de refúgio deferidos (enfatizando que nem todos os migrantes possuem status de refugiado). Embora não seja objetivo deste artigo entrar em tal discussão, observamos que dentro deste percentual não é possível mensurar a quantidade de indivíduos ou grupos provindos de migração forçada, mas que não se enquadram no que a lei prevê como refugiado.

${ }^{3}$ Para um relato mais detalhado acerca da criação e/ou processo inicial de implementação do projeto de extensão Português Brasileiro para migração humanitária PBMIH, ver Ruano, Pereti e Grahl (2016) e Cursino et al. (2016).
} 


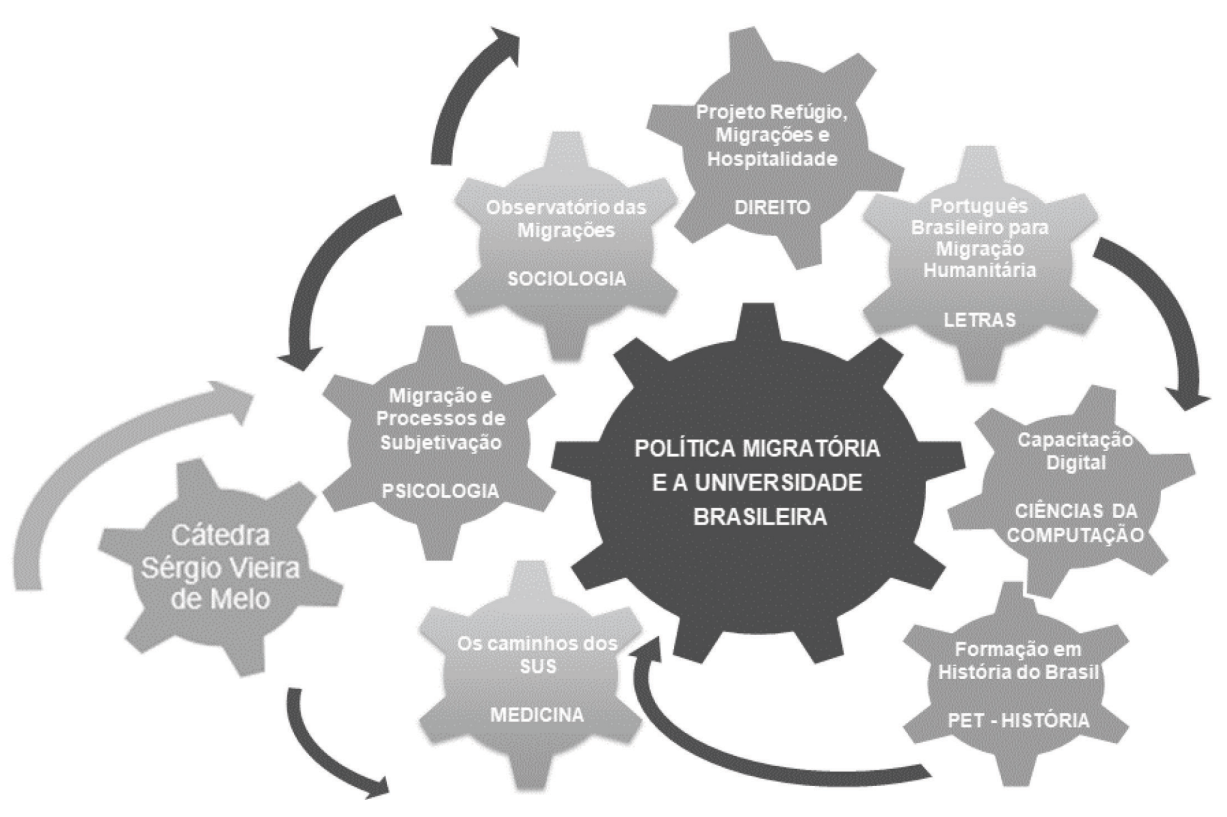

Figura 1: Estrutura organizacional

Fonte: as autoras (2020)

\subsection{PERFIL DOS ALUNOS}

Como exposto anteriormente, as atividades desenvolvidas pelo projeto são voltadas para migrantes com status de refugiados, portadores de visto humanitário e apátridas. Diante da dinamicidade dos fluxos migratórios contemporâneos ${ }^{4}$, o perfil dos alunos atendidos está em constante transformação. Contudo, desde o início do projeto, o maior contingente beneficiado é de cidadãos haitianos. Os últimos dados fornecidos pelo CONARE $(2018)^{5}$ mostram que no ano de 2018 o Brasil recebeu, aproximadamente, 80 mil solicitações de refúgio, sendo 61.681 apenas de comunidades venezuelanas. Após os solicitantes da Venezuela, se encontram os haitianos, com 7 mil solicitações.

Em 2019, o projeto acolheu 687 migrantes adultos e 22 migrantes crianças de diversas nacionalidades, a saber: Argélia, Argentina, Bolívia, Camarões, Colômbia, Congo, Cuba, Egito, El Salvador, Gana, Haiti, Iraque, Líbia, Marrocos, Nigéria, Peru, República Democrática do Congo, República Dominicana, Síria e Venezuela. O Gráfico 1 detalha a quantidade de alunos (eixo vertical) assistidos pelo projeto e seus países de origem (eixo horizontal).

\footnotetext{
${ }^{4} \mathrm{O}$ Brasil tem recebido um grande no número de refugiados, fugidos de seus países devido a catástrofes naturais (como o terremoto que devastou o Haiti em 2010), a guerras e suas nefastas consequências sobre civis (no caso de países como Síria e Congo), ou ainda a crises econômicas (Venezuela). Para uma discussão mais aprofundada, ver Oliveira (2016).

${ }^{5}$ Informação disponível no site do CONARE (2018): https://www.acnur.org/portugues/dados-sobre-refugio/dados-sobre-refugio-no-brasil/. Acesso em 14 de julho de 2020.
} 


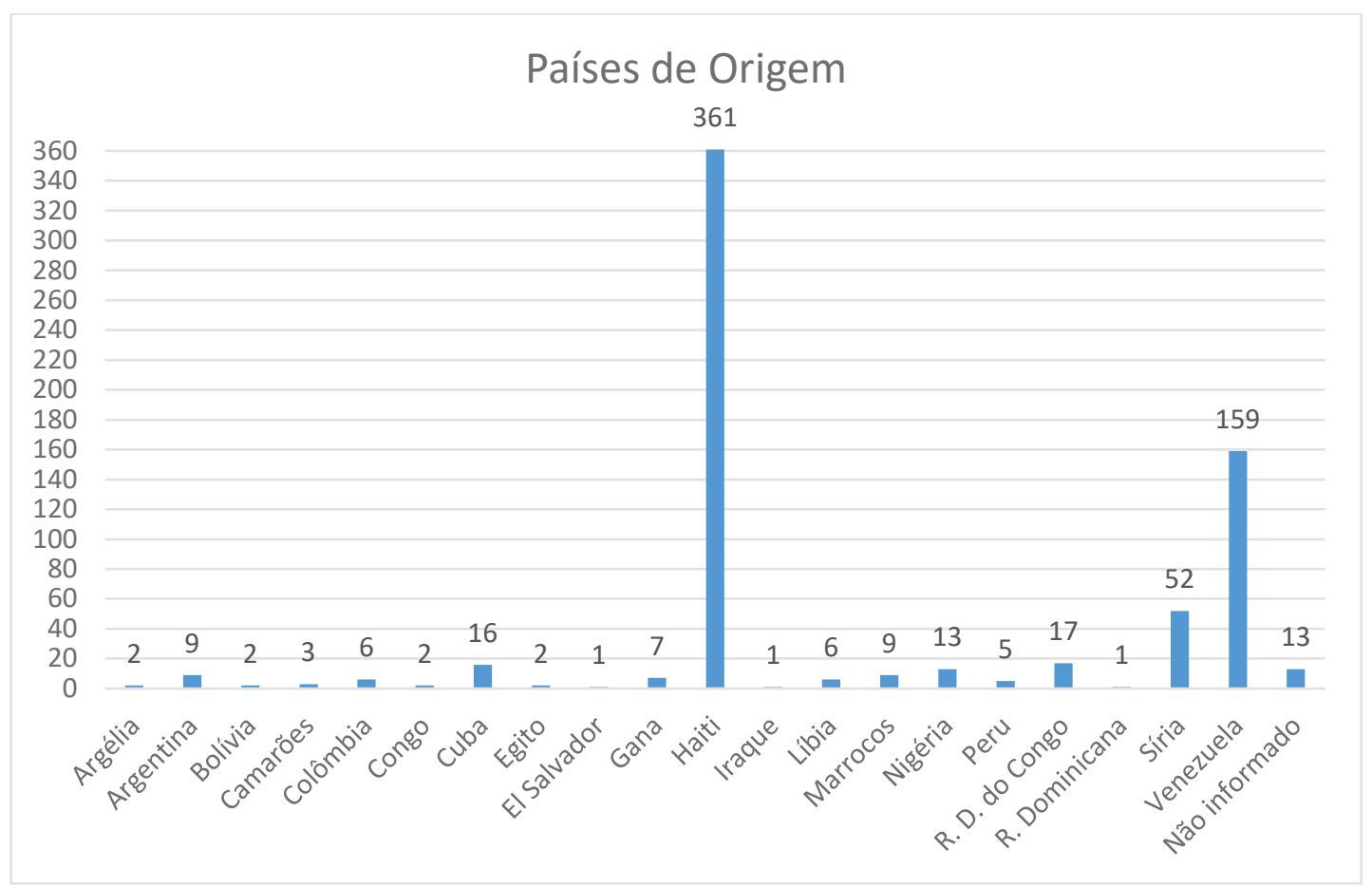

Gráfico 1: Países de origem dos alunos

Fonte: as autoras (2020)

Ainda referente ao perfil do público atendido, observamos nos últimos anos um aumento da população de alunos do sexo feminino. Atualmente, $35 \%$ dos alunos são do sexo feminino, 55\% do sexo masculino e $10 \%$ de não declarados, diferentemente do início do projeto, no qual a grande maioria do público atendido era composta por alunos do sexo masculino (86\% - dados do PBMIH de 2014). Em relação à faixa etária, o projeto continua com um público heterogêneo, 52\% dos alunos estão na faixa de 18 aos 35 anos, $33 \%$ na faixa dos 36 aos 55 anos, $9 \%$ na faixa dos 0 aos 17 anos e 6\% acima dos 56 anos.

\subsection{A EQUIPE}

O projeto é composto por uma equipe de professores, alunos de graduação, pós-graduação e ex-alunos da UFPR. No ano de 2019, o PBMIH possuía em torno de 45 estagiários, todos cursando ou formados em Letras pela UFPR. Ademais, o projeto é gerido por uma coordenação colegiada composta por Claudia Daher, Maria Cristina Figueiredo Silva e Maria Gabriel. Chamamos a atenção para o fato de que embora haja uma permanência dos membros da equipe de professores de português por cerca de 3 anos no projeto, há um processo seletivo de entrada para novos estagiários todos os semestres, de modo a garantir que a equipe possa ser a mais diversa possível, não só no que tange ao grau de formação acadêmica, mas também de experiência em outros projetos. Somando-se à equipe de professores de português, o projeto também conta com voluntários, acadêmicos de outras áreas do conhecimento (Design, Jornalismo e Psicologia), na oferta de cursos e subprojetos, os quais possuem seus conteúdos alinhados com as demandas trazidas pelos alunos das aulas de língua.

Visando atender ao objetivo principal do projeto, o acolhimento dos migrantes, ao longo desses anos, o PBMIH vem (re)construindo tecnologias educacionais ${ }^{6}$ voltadas ao ensino-aprendizagem de português como Língua Adicional. Para tanto, nossas práticas são pautadas em um diálogo permanente e respeitoso com os migrantes e suas organizações, para compreender suas realidades, identificar suas demandas e trabalhar em propostas visando à mitigação de suas necessidades e de sua vulnerabilidade, na perspectiva do fortalecimento de sua autonomia para a defesa de seus direitos.

\footnotetext{
${ }^{6}$ Para uma discussão mais aprofundada acerca dos conceitos de língua, metodologias, protocolos de ação utilizados e desenvolvidos no âmbito do PBMIH, ver Cursino et al. (2016).
} 
Assim, desde o início do projeto, todas as nossas ações são desenvolvidas para atender as especificidades dos alunos, a saber: a) o cadastro de novos alunos: em cada aula é possível a inserção de um aluno novo, o projeto conta com uma equipe de nivelamento que é especializada no recebimento e acolhimento de novos participantes; b) o formato do curso: porta-giratória ; c) o material didático: todo material didático é desenvolvido pelas equipes que compõem o projeto, cada equipe envia o material que usará na aula para a coordenação do projeto e será impresso horas antes da aula. Essa logística possibilita que os professores possam abordar temáticas e/ou acontecimentos recentes e de especial interesse para a população de migrantes atendida; d) cursos oferecidos: além dos cursos tradicionalmente disponibilizados, o projeto oferta cursos sazonais, frutos das demandas trazidas pelos alunos. Por exemplo, em 2018, ofertamos o preparatório para o exame de Certificação de Proficiência em Língua Portuguesa para Estrangeiros (CELPE-BRAS). Tal demanda emergiu de uma nova exigência do governo brasileiro para migrantes que pretendiam naturalizarse; e) níveis ofertados: a quantidade de turmas e os níveis são ofertados a partir da procura e perfil dos alunos (respeitando, evidentemente, nossas limitações de espaço físico e pessoal para dar as aulas). Em 2018, pela primeira vez, abrimos uma terceira turma de pré-intermediário direcionada a hispanos recém-chegados ao Brasil.

A Figura 2 ilustra os encaminhamentos que norteiam as nossas ações:

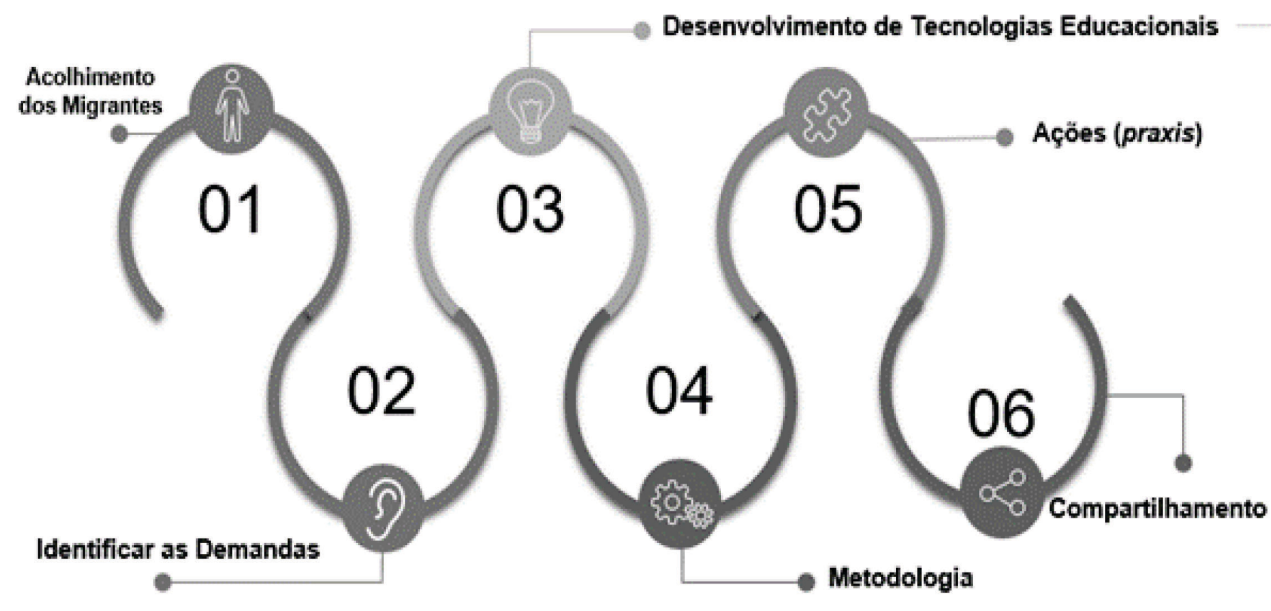

Figura 2: Nossas práticas

Fonte: as autoras (2020)

Ao observarmos a Figura 2, podemos notar que as ações do projeto se iniciam no acolhimento e na escuta da população atendida. Além disso, é mister apontar que nossas ações são planejadas a partir desse primeiro momento, contudo, o sequenciamento delas não se desenvolve de maneira linear, mas em uma espécie de espiral de forma que as etapas se conectam e se realimentam. Ademais, esse processo de desenvolvimento e ação que permeia nossas práticas se dá tanto no nível macro (organizacional/coordenação) quanto no micro (sala de aula).

Dessarte, nestes últimos anos (2018, 2019 e 2020), as ações do projeto resultaram em diversas atividades culturais: a) a campanha "Ser Migrante - Vozes e Culturas na UFPR" (2018), com apresentação cultural no Teatro Guaíra; b) o lançamento da $7^{\circ}$ edição da revista TOM da UFPR (2018) - “Andanças: travessias da migração e do refúgio”; c) a criação (2019) e lançamento da primeira edição da Revista Ressonâncias (2020), a qual se debruça sobre a disponibilização de materiais didáticos abertos para o ensino de português (entre outros assuntos) a migrantes ; d) a oferta de um curso de bordado e encadernação para mulheres migrantes (2019), realizado pela "Entrelaços", subprojeto dentro do PBMIH; d) produção de materiais informativos sobre o novo coronavírus (2020), políticas públicas e auxílio financeiro em seis línguas (Português, Espanhol, Francês, Crioulo Haitiano, Árabe e Inglês); e) os eventos de troca cultural, os quais se manifestam na forma de "festas de encerramento" e operam como uma plataforma a mais para que haja a escuta de múltiplas vozes. Ademais, no segundo semestre de 2019, o projeto ofertou 16 turmas: 2 turmas de Básico I, 2 turmas de Básico

\footnotetext{
${ }^{7}$ Uma vez que a população atendida é constituída por pessoas que estão em deslocamento forçado e que chegam a todo momento ao país, o formato tradicional de curso não atenderia essa especificidade. Para tanto, nos utilizamos de uma metodologia intitulada "porta-giratória" que consiste basicamente em uma aula que abre e fecha nela mesma e prevê a entrada e/ou a saída de um aluno em qualquer momento. Para uma discussão mais aprofundada, ver Cursino et al. (2016).
} 
II, 2 turmas de Pré-Intermediário, 2 turmas de Intermediário I, 2 turmas de Intermediário II, 1 turma de Avançado, 1 turma da Entrelaços: Bordando identidades, narrativas e percursos, 2 turmas de Crioulo Haitiano (curso ministrado por migrantes haitianos que terminaram todos os níveis de português ofertados pelo PBMIH) 1 turma de Crianças (a turma de crianças é destinada aos filhos dos alunos que fazem aula no projeto; atualmente, a ação com as crianças tornou-se o projeto de extensão Pequenos do Mundo, coordenado pela professora Graziela Lucchesi (Psicologia), o Pequenos do Mundo é uma ação interdisciplinar entre as áreas da psicologia, letras, comunicação e artes cênicas. Essa demanda é fruto da observação das mulheres que frequentavam nossas aulas e começaram a faltar com frequência. Assim, decidimos criar uma turma de crianças para que, enquanto as mães estudassem, os filhos pudessem participar de atividades adequadas a suas idades) e $\mathbf{1}$ turma de formação para professores (essa turma é um espaço de formação inicial e continuada dos professores do projeto que são graduandos e pósgraduandos. Caracteriza-se como um momento de diálogo e troca de experiências, além de um espaço para a sistematização das ações implementadas. Tal iniciativa surgiu uma vez que no curso de Letras da UFPR não dispomos de uma habilitação e/ou especialização em PLA, tampouco uma formação voltada ao ensino-aprendizagem do PB direcionada a migrantes em contexto de refúgio).

Outro desdobramento do projeto se refere à formação dos professores que nele atuam. Visto que, como supramencionado, a equipe é constituída por professores em diversos estágios da formação, suas trajetórias são bastante heterogêneas, uma vez que alguns possuem experiência de docência com outras Línguas Adicionais, mas não em PLA, outros possuem experiência como professores de Português, mas não necessariamente como PLA, e muitos ainda se encontram em processo de formação inicial e nunca haviam pisado em uma sala de aula enquanto docentes. Assim, poucos iniciam suas atividades no projeto possuindo experiência em PLA.

Com base na composição do quadro docente, a paisagem de docência em projetos como o PBMIH não poderia ser mais variada e rica. Os alunos, por sua vez, apesar de se encontrarem em situações relativamente semelhantes de chegada, provêm de diferentes países, culturas de ensino-aprendizagem, relações com o Português, experiências de vida, faixas etárias etc. Consequentemente, a sala de aula de PLA no contexto de ensino-aprendizagem para estas comunidades de migrantes é vista como um espaço de primeira acolhida, de troca de desejos e ansiedades cotidianas e, por vezes, um dos poucos espaços em que os alunos se manifestam e trocam experiências significativas com outros migrantes e brasileiros ${ }^{8}$.

No entanto, o mosaico formado a partir dessas diferentes identidades em construção gera momentos críticos, com os quais é possível retroalimentar o processo de formação inicial e continuada dos docentes de projetos como o PBMIH-UFPR, bem como a construção de currículos que se preocupem essencialmente com uma problematização da praxis, conforme aponta Pennycook (2004).

\section{MOMENTOS CRÍTICOS NA SALA DE AULA DE PLA: TRABALHANDO RUMO A UMA PRÁTICA INFORMADA}

É mister ressaltar que há uma diferença essencial entre os entendimentos do termo "crítico", como enuncia Pennycook (2004). No contexto em que nos inserimos neste artigo - o de ensino-aprendizagem e formação inicial e continuada de professores de PLA para comunidades migrantes - o termo ensino-aprendizagem crítica surge quase como que uma condição sine qua non. No entanto, tal condição pode operar em um nível superficial (assumindo que o trabalho com migrantes em situação de vulnerabilidade social é sempre crítico) ou com maior profundidade (a prática reflexiva a partir da ciência explícita dos incidentes e momentos críticos provindos das aulas). Nesta discussão, nos preocupamos com a segunda vertente, a qual Pennycook (2004) aponta como sendo problematizadora da prática, propulsionando

\footnotetext{
${ }^{8}$ Tal registro é parte da experiência da autora como uma das coordenadoras e docentes do projeto PBMIH-UFPR, no atendimento dos alunos do curso.
} 
[...] um modo de trabalhar na educação linguística que não reduz o trabalho crítico nem ao domínio do pensamento crítico, nem à dialética rasteira das relações micro e macro e, ao mesmo tempo, traz à tona questionamentos sobre linguagem/língua, discurso, poder e identidade.9 (PENNYCOOK, 2004, p. 334)

Tal assunção parece dialogar intimamente com o ensino de PLA para comunidades de migrantes, uma vez que o micro poderia ser localizado no chão da sala de aula; o macro, por sua vez, na gerência de projetos como o PBMIH e os eventos externos ao projeto, os quais afetam brasileiros e migrantes em um cenário político-social mais amplo. Nessa esteira, tanto no plano micro quanto no macro, defendemos que a ocorrência de momentos críticos opera como mola propulsora de formação e construção de currículo.

De acordo com Farrell (2008, p.3), “[...] um incidente crítico é qualquer evento não-planejado que ocorre durante uma aula ${ }^{10 ”}$. Na mesma esteira, Pennycook (2004, p. 330), menciona que os momentos críticos aparecem quando "[...] aproveitamos a chance de fazer algo diferente, quando notamos que algum novo entendimento está por vir ${ }^{11}$ ”. Em tal visão, notamos um processo de ciência explícita por parte dos indivíduos em relação aos incidentes críticos que provocam mudanças em suas aulas e estados de agência, na tentativa de resolução de tais momentos. Outros autores, como Woods (2012, op cit. p.1), oferecem mais detalhes quanto à natureza de tais momentos, mencionando que esses são "não planejados, imprevisíveis e incontroláveis 12". Tendo em mente essa definição, observamos que se trata de momentos bastante orgânicos, os quais podem gerar episódios conflituosos para os docentes, uma vez que ocorrências dessa natureza não fazem parte a priori de seus planos de aula e, muitas vezes, de seu repertório de soluções. Em relação à formação inicial de professores de Línguas Adicionais, a reflexão sobre tais momentos críticos em sala de aula podem possibilitar novos entendimentos no processo de docência.

Dada a não previsibilidade de tais momentos, autores como Woods (2012, p.8-9) procuram definir estágios de agência sobre tais eventos, a saber: a) conceitualização; b) preparação e planejamento; c) divergência; convergência; d) consolidação. Os primeiros estágios, acima mencionados nas letras "a" e "b", estão relacionados com partes comparáveis à rotina de planejamento de vários professores, a qual conta com uma conceitualização sobre os tópicos que serão abordados e como tratá-los. No entanto, diferentemente da rotina de preparação do plano de aula, dada a imprevisibilidade dos momentos críticos, tal conceitualização, preparação e planejamento não se dão a priori, mas sim a posteriori ou no momento em que a aula já se encontra em andamento. $\mathrm{Na}$ contraparte dos alunos, para o autor, tais estágios se relacionam com momentos criativos que surgem de assuntos ou situações decorrentes da proposta do professor e sobre os quais os alunos planejam ações. Os estágios "c" e "d" contemplam ações que se complementam, uma vez que durante os momentos de criatividade, os alunos e o professor optam por expandir para/em reflexões maiores, que geralmente atingem o plano macro e não apenas micro. O último estágio, por fim, estaria relacionado com a etapa de junção e (re)elaboração das reflexões de todo o processo criativo, no qual todas as partes ainda possuem suas propriedades primárias, mas são ampliadas com a conexão compartilhada criada com o grupo.

Em suma, ao recorrermos ao espaço de atuação aqui delimitado, alguns dos estágios descritos por Woods (2012) são passíveis de serem encontrados nas ações desenvolvidas pelo PBMIH. Por ora, buscaremos analisar as narrativas de professores em formação inicial e continuada do projeto, de forma a entender a natureza desses momentos críticos, o papel de professores e alunos e as reformulações no ambiente de atuação micro e macro.

\section{METODOLOGIA}

Como mencionado anteriormente, o estudo pretende refletir sobre o papel dos incidentes/momentos críticos nos processos de negociação entre professores e alunos do curso de PLA no projeto PBMIH-UFPR. Para tanto, optamos por uma metodologia que

\footnotetext{
${ }^{9}$ No original: “[...] a way of working in language education that doesn't reduce critical work either to the domain of critical thinking or to crude dialectics between micro and macro relations and, at the same time, keeps questions of language, discourse, power, and identity to the fore."

${ }^{10}$ No original: "A critical incident is any unplanned event that occurs during class."

${ }^{11}$ No original "[...] when we seize the chance to do something different, when we realize that some new understanding is coming about".

${ }^{12}$ No original: "They are unplanned, unanticipated and uncontrolled."
} 
destacasse voz aos participantes, professores do projeto. Assim, esta seção está organizada de modo a descrever a metodologia utilizada, o perfil dos sujeitos e o protocolo de entrevista para geração de dados ${ }^{13}$.

\subsection{SUJEITOS}

Objetivando alcançar as metas traçadas para este trabalho, foram entrevistados quatro professores que atuam no PBMIH. Os sujeitos foram selecionados visando assegurar uma maior representatividade da diversidade encontrada no projeto. Para tanto, procuramos entrevistar professores que tivessem tempo de experiência e grau de escolaridade diferentes, além de atuarem em níveis distintos.

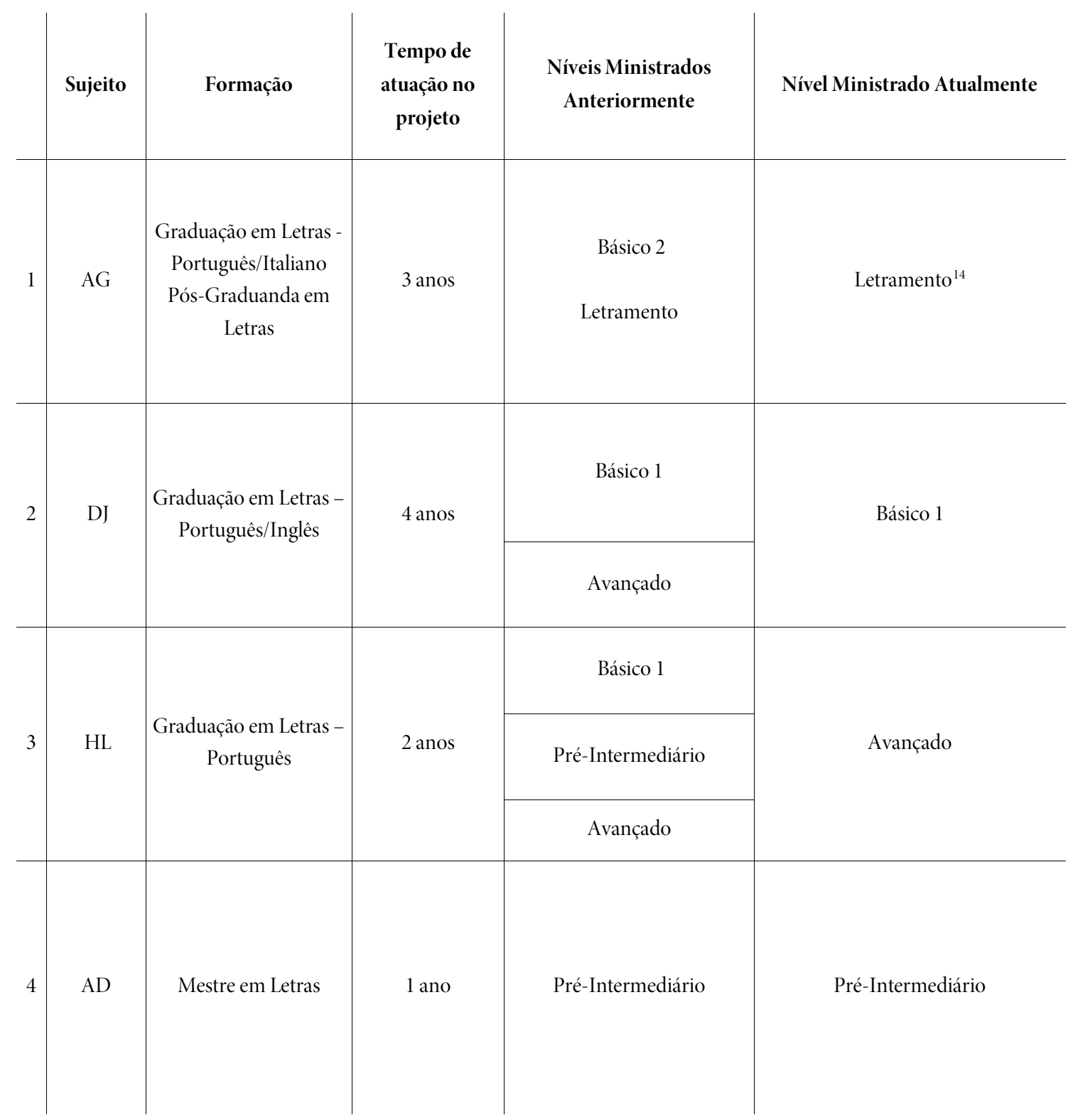

Quadro 1: Perfil dos sujeitos

Fonte: as autoras $(2020)$

\footnotetext{
${ }^{13}$ Chamamos a atenção para o fato de que este projeto faz parte de outro maior, encaminhado ao Comitê de Ética em Pesquisa da UTFPR(Universidade Tecnológica Federal do Paraná), sob o número 2.812.011.

${ }^{14}$ Letramento é um nível voltado para migrantes que não passaram por um processo de ensino formal em seus países de origem. A abertura da turma depende da demanda de migrantes com esse perfil.
} 


\subsection{PROTOCOLO DE ENTREVISTA}

Optou-se por um instrumento que permitisse uma interação mais livre entre a pesquisadora e os participantes, sem que a rigidez de uma entrevista fechada e/ou estruturada pudesse inibir ou não considerar informações importantes. Para tanto, elencamos questões norteadoras que proporcionassem um diálogo entre a pesquisadora e os participantes, visando explorar um espectro de elementos relativos à temática pesquisada.

Em relação aos procedimentos metodológicos que viabilizaram a geração dos dados. Primeiramente, os participantes receberam um termo de consentimento, foram informados da não obrigatoriedade da entrevista e que teriam a liberdade de se recusar a participar sem que isso lhes ocasionassem qualquer tipo de prejuízo. Nesse momento, eram instruídos sobre a natureza da entrevista: a) a conversa não media tempo, assim, o participante poderia responder com a calma necessária; b) eles poderiam voltar e retomar alguma informação a depender da lembrança de algum fato ou informação que julgassem importante; c) não existiam respostas certas ou erradas. Além disso, as entrevistas foram realizadas individualmente, no mesmo local, pela mesma pesquisadora e conduzidas de forma que todas perguntas foram direcionadas aos sujeitos na mesma sequência.

As perguntas que nortearam as entrevistas se encontram dispostas abaixo:

1. Como você se tornou um professor de Português como Lingua Adicional? O que é ser um professor de PLA no seu contexto?

2. Para vocêe importante ser um professor crítico? Se sim, o que você entende por crítico (ser um professor crítico)?

3. Comente algum episódio em que você explorou um momento de sala de aula para uma atividade crítica, ou que tenha possibilitado um posicionamento crítico seu e de seus alunos. De que forma tal episódio foi explorado?

4. Comente algum episódio de sala de aula em que você sentiu dificuldades para se posicionar criticamente.

\section{DISCUSSÃO E ANÁLISE}

Nesta seção, faremos a análise de trechos das entrevistas realizadas com os 4 sujeitos, professores do PBMIH. Por uma mera questão de organização, optamos por separar por questão e por expor as respostas na ordem em que elas foram apresentadas na entrevista.

\section{Questão 1 - Como você se tornou um professor de Português para falantes de Outras Línguas? O que é ser um professor de} PLA no seu contexto?

Todos os entrevistados iniciaram suas atividades de professores de Português como Língua Adicional no âmbito do projeto. Nenhum dos entrevistados tinha dado aula de PLA anteriormente. Entretanto, somente o sujeito AD possuía experiência como professor de Língua Adicional, mas não de Português como Língua Adicional.

Em relação ao contexto de ensino, as respostas versam acerca da complexidade de trabalhar com a população de migrantes em contexto de refúgio e em vulnerabilidade social. Ademais, ressaltaram a importância do desenvolvimento de uma sensibilidade por parte do professor desde os horários de aula, até as temáticas abordadas, os contextos e as experiências vividas pelos alunos, como indicamos trechos selecionados abaixo:

AG: No PBMIH, a gente dá aulas de português para os refugiados, migrantes, pessoas que estão aqui em busca de uma nova oportunidade. Então, não é aquele perfil de estudante de língua que vai viajar... Aqui, ele precisa de outras ferramentas, ele precisa acessar a sociedade e agir no mundo como qualquer outro cidadão daquele local ou daquela região. 
DJ: Não é só dar aula de português, porque a gente tá lidando com realidades muito diferentes e com alunos que chegam com problemas o tempo todo, até o fato que você está dando aula em um sábado à tarde... às vezes você vai lá no mercado e compra umas coisas para fazer o lanche com eles, porque se vocêd er o intervalo, ninguém vai na cantina comprar lanche, ninguém vai trazer um lanche.

HL: Ser professor nesse contexto é difícil, na verdade, quando as pessoas perguntam eu falo que comecei já com a parte mais difícil, que é lidar com esse público de refugiado. Por conta do cuidado que você tem que ter na preparação das aulas, do que fala, como você fala, tem várias situações que você precisa ser muito cuidadoso, por exemplo, o uso do passado, em uma sala tradicional você vai pedir para a pessoa contar o que ela fez nas férias. Mas em uma sala do PBMIH, eles acabaram de sair de uma guerra...

AD: Ser professor já é complexo e significativo e muito recompensante, só que nesse contexto, é mais ainda, justamente, porque é mais imediato, é mais urgente, é mais significativo, além de complexo.

Questão 2 - Para você, é importante ser um professor crítico? Se sim, o que você entende por crítico (ser um professor crítico)?

Todos os sujeitos responderam que é extremamente importante ser um professor crítico. Em relação ao entendimento do que significa ser um professor crítico, as respostas versaram, em geral, acerca do professor possibilitar um espaço de diálogo, de questionamento, de construção de respostas e não de uma verdade absoluta. Além disso, o sujeito DJ acrescentou a relevância de considerar o perfil dos alunos e o contexto em que estão inseridos. Ademais, o sujeito HL ressaltou a importância de o professor conhecer as questões geopolíticas das quais os alunos advêm. É possível verificar essas questões nos trechos abaixo:

AG: não consigo imaginar um ensino não crítico... Você tem que colocar seu ponto de vista, mostrar que não é o único, que existem outros... O professor crítico é o que é capaz de proporcionar um diálogo de opiniões diferentes e conseguir mediar.

DJ: Acho que ser crítico é você considerar, os alunos que você tem, selecionar o material e pensar no contexto também que você está culturalmente falando e no contexto do aluno... Acho que ser crítico é considerar vários contextos e conseguir trazer perspectivas para a sala de aula, é um trabalho bastante complexo.

HL: Ser professor crítico é você estudar e ter uma sensibilidade, em você conhecer os temas, saber como falar. Você tem que estudar, por exemplo, você não pode entrar em uma sala com refugiados sem você conhecer o que foi a guerra na Síria, sem saber o que é um muçulmano, o que é um cristão. Você tem que ter uma série de conteúdos, não que necessariamente você vai entrar nesses conteúdos na sala de aula, mas você tem que ter esse background para você saber como lidar com essa questão... Ser crítico é você saber, conhecer esses assuntos, para você saber como lidar com isso em sala de aula. Então, é essencial.

AD: É você apresentar as coisas, mas apresentar com possibilidades, não apresentar como é isso e acabou, como a verdade. Mas que verdade é essa, porque que essa é a verdade? Eestimular isso nos alunos também, não necessariamente a minha opinião que é a opinião certa de professora, mas tá gente, existe isso aqui que é tido como verdade, existe essas outras possibilidades, vamos pensar sobre, por que isso é verdade? por que aquilo não é? Isso para mimé ser professor crítico.

Questão 3 - Comente algum episódio em que você explorou um momento de sala de aula para uma atividade crítica, ou que tenha possibilitado um posicionamento crítico seu e de seus alunos. De que forma tal episódio foi explorado?

Tal pergunta nos possibilita adentrar um pouco mais nos dilemas diários das aulas dentro do projeto PBMIH-UFPR, uma vez que ao falar sobre os momentos críticos, os professores elaboraram sobre processos de negociação, mediação, papel da formação inicial e/ou continuada na resolução dos conflitos etc. De modo geral, todos os participantes entrevistados convergiram suas respostas para a menção de que todas as aulas ministradas no projeto possuem situações-conflito, nas quais os professores precisam replanejar a discussão e reprogramar as aulas seguintes para acomodar questões adjacentes ao conflito gerado. 
Mais especificamente, um dos aspectos elencados por alguns dos professores foi a negociação de estratégias entre ambos os professores regentes da turma. Conforme mencionado anteriormente, o projeto PBMIH-UFPR opera com mais de um professor por turma e tal aspecto gera uma docência compartilhada. Um dos momentos críticos que evidencia tal dinâmica entre os professores pode ser visualizado no comentário da participante AG.

AG: O mais chocante que aconteceu para mim até hoje foi em aula que estávamos falando sobre..., na verdade, não me lembro exatamente o tema da aula, mas sei que surgiu uma questão, em que o aluno disse que os homens eram superiores às mulheres. No dia, tinha comigo uma outra professora que ficou muito indignada, que se ofendeu, levou para o lado pessoal, lembro que ela levantou exaltada e eu falei calma, deixa ele falar. Pedi pro aluno explicar o que ele queria dizer com isso [...]

O momento crítico gerou em todos os participantes, alunos e professoras, uma reorganização do plano de aula para atender a demanda emergencial. AG optou por tomar uma via de comunicação distinta da colega, procurando fragmentar e, ao mesmo tempo, localizar os argumentos do aluno, de modo a descobrir de onde vinham os argumentos de que ele estava lançando mão e como tal discussão operava para ele, em seu país de origem, bem como nos países dos demais alunos. AG continua dizendo que

AG: O meu papel neste momento, não era só como professora ou como mulher que tinha que rebater o homem que dizia que era superior a mim, mas era fazer ele entender que ali ele podia falar, mas que eles tinham lugares que não e que minha sociedade é um pouco diferente que a dele, mas nem tanto.

Notamos que o evento crítico inseriu um momento de divergência entre professores e alunos, mas ao mesmo tempo de convergência entre as docentes, para procurar focar a resolução do conflito.

$\mathrm{Na}$ esteira de se pensar em como atender os conflitos gerados em sala de aula, um dos participantes comentou como os momentos críticos ocorridos auxiliam na elaboração das aulas seguintes e como o programa do curso precisa se manter aberto para acomodar esses momentos. A partir do evento crítico abaixo mencionado, notamos como há uma retroalimentação do programa a partir do momento crítico ocorrido.

AD: [...] lembro, especificamente de um dia, que a gente tinha um aluno, que tinha uma certa dificuldade de interação em sala de aula, né, às vezes ele se exaltava, falava por cima das pessoas e queria ser o representante do Haiti, o porta-voz da cultura haitiana. Lembro que depois de ter um episódio de tensão, dele exaltado, dele discutindo com outro aluno, nós pensamos em trabalhar com a temática de educação, respeito, turnos de fala, então, planejamos umas aulas em cima disso e particularmente acho isso um bom exemplo.

Por fim, é importante observar o papel da observação na formação inicial informada. Um dos participantes trouxe um momento crítico que o instigou a refletir sobre o status quo retratado em sala de aula quando trabalhamos com temáticas polêmicas, como é o caso da constituição da família no Brasil. Neste episódio, observamos como o momento crítico influenciou o planejamento de futuras aulas da professora em formação inicial (na época do fato ocorrido), a qual hoje narra o episódio.

DJ: Lembro que para os alunos, que no geral eram bastante religiosos, não tem nada a ver com eles serem estrangeiros, mas com a questão da religião e para essa comunidade mais religiosa foi uma aula que foi de enfrentamento. Nessa época, eu mais observava, estava no começo, eu lembro que foi todo um embate, porque assim...não vou considerar que foi ruim, foi legal porque um aluno que está no básico, que não consegue tanto assim falar português, por ele ter sido cutucado e por isso conseguir falar e desenvolver o ponto de vista sabe, de uma maneira bem legal. Mas eu lembro que usando esse episódio, quando eu fui planejar outras aulas de família, eu pensei sempre em trazer essa coisa de que existe vários tipos de família, mas trazer de uma maneira um pouco mais sutil para ser uma maneira de enfrentamento e o aluno aí, essa professora, sei lá, de certa maneira até se fechar, porque a gente sabe como é difícil lidar com pontos de vista diferentes. 


\section{Questão 4 - Comente algum episódio de sala de aula em que você sentiu dificuldades para se posicionar criticamente;}

Em relação a momentos e/ou situações críticas, aos quais os professores entrevistados tiveram dificuldades em administrar em sala de aula, podemos observar que, normalmente, essas situações são decorrentes da especificidade do público atendido, migrantes com status de refugiados e/ou em vulnerabilidade social. A natureza desses incidentes provém, em grande medida, das experiências vividas anteriormente pelos alunos, que resultaram no processo migratório forçado e, consequentemente, na obrigatoriedade de inserção na nova comunidade, mediada pelo aprendizado da nova língua. Deste modo, podemos encontrar na narrativa dos professores relatos relacionados a situações dramáticas resultantes de experiências vividas em ocasiões de guerra, desastre, conflitos armados e - principalmente - um sentimento de perda e o vazio.

AG: Era uma apresentação oral, eu pedi um tema qualquer que não lembro agora, sei lá... sobre comida, uma coisa assim, que não tinha muito a ver com o momento. A aluna foi falar do país dela e não conseguiu apresentar porque se emocionou e começou a chorar, e eu não sabia o que fazer nessa hora.

HL: Em uma aula sobre partes da casa... uma aluna falou que tinha fotos da sua casa com ela e pediu para mostrar "deixa eu mostrar" ... e todo mundo falou... "ah! deixa eu ver a tua casa". Só que a foto que ela mostrou era uma ruína, na verdade. Ela era uma aluna síria e ela mostrou as fotos da casa toda destruida e ela falava aquilo com muito amor, olha aqui... e era uma ruína, não dava muito para ver o que era o que... mas ela falava... aqui eu estendia a minha roupa, aqui os meus filhos brincavam... e os alunos da sala olhavam e todo mundo ficou com aquela cara, sem saber o que dizer.... Outro aluno, em um determinado momento contou a história dele, ele era desertor do exército do país dele e que ele tinha fugido para o Brasil, porque ele estava cansado de ver criança morta, porque no país dele, quando ele era militar, ele era obrigado a entrar nos lugares e ele via muita criança morta e aquilo mexia muito com ele, então, ele fugiu do país dele.

Nos relatos supracitados, podemos observar também que esses momentos surgem independentemente do contexto e/ou temática abordada em aula, essas situações podem emergir em diferentes momentos, em diferentes situações como ressalta Woods (2012) são momentos e/ou situações não planejadas, imprevisíveis. Contudo, apesar de surgirem em momentos inesperados, os professores do projeto relataram que - devido ao curso de formação proporcionar uma troca de experiência - eles têm ciência que essas situações são recorrentes e podem aparecer em qualquer momento da aula.

AG: Eu ouvia os professores que trabalhavam com esse público falar de como é delicado, né, de falar de questões do seu país, por exemplo, como é no seu país, como foi na sua infância etc. Eu entendia que isso podia acontecer.

Apesar de o curso de formação proporcionar a troca de experiência, possibilitar o conhecimento e a reflexão crítica como aponta Pennycook (2004), os entrevistados mencionaram que, ainda assim, encontram dificuldade em agir no momento que a situação acontece.

AD: A discussão entre os professores é importante, mas às vezes só passando pela situação você sabe o que realmente é.

HL: Eu sabia, mas aquilo entra na tua sala e te atropela que por mais preparado que esteja, estude e leia a respeito, você não está preparado. E ao entrar em contato com aquela pessoa, ela está na sua frente e você não sabe o que aqueles olhos já viram, o que ela passou, o que ela sentiu, o que passou naquela cabeça. Então, você fica muito, muuuitooo... chateado.

Contudo, embora os relatos apontem uma dificuldade e/ou um estranhamento com as situações, se analisarmos mais atentamente as narrativas, podemos observar que os professores com mais ou menos experiência agem de diferentes maneiras nessas ocasiões. Assim, ao voltarmos aos estágios propostos por Woods (2012), podemos classificar os sujeitos a depender do tempo de experiência. Para tanto, ao verificarmos o trecho supracitado do sujeito AD (1 ano de experiência), esse parece encaixar-se dentro das primeiras etapas ((a) conceitualização e (b) preparação e planejamento), uma vez que essas etapas preveem que o tratamento crítico se dá de forma a posteriori ao ocorrido. Nesse mesmo sentido, o sujeito AD complementou: 
AD: Acho que é mais produtivo quando você vive a situação e comenta sobre, porque mesmo que você tente teorizar e prever o que pode acontecer, nunca é igual ao momento que acontece de fato. Acho que é mais fácil lidar quando acontece e você fala, porque, talvez, se acontecer em um outro momento você saiba lidar.

Os demais entrevistados, apesar do incômodo com as situações, parecem agir de maneira mais próxima do que é previsto nos estágios (c) divergência/ convergência e (d) consolidação. Nesses estágios, o professor, parece lidar de forma mais “tranquila” com a situação, com uma espécie de repertório de ação internalizado.

DJ: Teve um episódio que o aluno começou a comentar da guerra, a minha postura já foi uma postura de quem esperava que isso poderia acontecer, eu sei que não é nada que eu tenho que falar, ou fazer, mas que eu preciso proporcionar o momento de escuta e deixar ele comentar e foi muito mais tranquilo. Claro que não foi 100\%, porque nunca é, mas com certeza a troca de experiência e o tempo no projeto ajudou.

HL: Você sabe lidar com aquilo de uma maneira mais sensivel, você saber a hora de parar, de não perguntar, você consegue ficar acalmo, e você saber ouvir o que ele está falando, deixar ele falar, que se expresse e tudo mais, às vezes ele precisa soltar aquilo de alguma maneira.

\section{CONSIDERAÇÕES FINAIS}

Ao longo desta discussão, trabalhamos com a temática da reflexão acerca de momentos críticos flagrados no interior da sala de aula de PLA, a partir das narrativas de quatro docentes do projeto PBMIH-UFPR. Notamos que as narrativas de incidência de momentos críticos são delineadas de acordo com as experiências dos professores dentro e fora do projeto, as quais parecem estar intimamente conectadas com a experiência ou inexperiência com ensino de Línguas Adicionais, tempo de docência em PLA e, mais especificamente, no ensino de PLA a comunidades de migrantes. Com isso, não queremos imprimir um tom de julgamento em relação à quantidade de experiência em sala apresentada pelos professores, no sentido de direcionar a conclusão para um cenário em que professores mais experientes tomam decisões mais adequadas do que os que possuem menos experiência. Pelo contrário, apesar de a experiência ser um aspecto que compõe a identidade dos docentes entrevistados, notamos que as decisões parecem acontecer em sala de aula, independente da experiência, mas elas acontecem de modos diferentes, com encaminhamentos distintos.

As narrativas acabam por retratar um mosaico em construção, uma vez que, conforme Farrell (2008), ao passo que os professores refletem criticamente sobre suas jornadas enquanto docentes, há a emergência de um processo de reconhecimento e análise que muitas vezes se concretiza em ações. O autor ainda incentiva a prática de observação como primordial para que se examinem os momentos críticos e os possíveis encaminhamentos para eles. Chamamos a atenção, também, para a natureza dessas ações. Estas não precisam ocupar o lugar de decisões categóricas acerca do grupo, de modo a generalizarmos que em todos os momentos que situações semelhantes ocorram, poderemos aplicar o mesmo encaminhamento. Situações semelhantes podem requerer ações/decisões diferentes, mas o que muda a cada enfrentamento de momento crítico são as ferramentas que os professores carregam consigo, suas experiências adquiridas e compartilhadas com seus pares.

De modo geral, vários dos momentos críticos que foram mencionados estavam relacionados a um evento que desencadeou mudanças futuras no planejamento do curso. Além disso, os momentos de formação docente ofertados pela coordenação do projeto, a mediação dos alunos em sala, a negociação de estratégias por parte dos outros professores, fazem parte de um aprendizado acerca de um momento crítico, aprendizado esse que é sempre dinâmico e não-linear.

A partir do cenário acima exposto, este trabalho espera ter contribuído para uma visão mais aprofundada sobre o papel dos incidentes/ momentos críticos na formação inicial e continuada de professores de PLA, especialmente de comunidades migrantes. Entendemos que os cursos ou espaços de formação inicial e continuada de docentes poderiam se beneficiar de momentos de trocas, nos quais os enunciados - como os produzidos pelos participantes desta pesquisa - tenham lugar de fala e possam ser utilizados como pontos de construção compartilhada entre o grupo de professores. 


\section{REFERÊNCIAS}

ALMEIDA FILHO, J. C. P. Ensino de português língua estrangeira/EPLE: a emergência de uma especialidade no Brasil. In: LOBO, T. et al. (org.). Rosae: linguística histórica, história das línguas e outras histórias [online]. Salvador: EDUFBA, 2012. p. 723-728.

CONARE - Comitê Nacional para os Refugiados. Relatório - dezembro 2017 à dezembro 2018. Refúgio em Números. Brasília, DF: ACNUR, 2020. Disponível em: https://www.acnur.org/portugues/dados-sobre-refugio/dados-sobre-refugio-no-brasil/. Acesso em: 14 jul.2020.

CURSINO, C. et al. Português Brasileiro para Migração Humanitária (PBMIH): reflexões linguísticas e pedagógicas para o ensino de PLE em contexto de migração e refúgio. In: RUANO, B. P.; SANTOS, J. M. P.; SALTINI, L. M. L. (org.). Cursos de português como língua estrangeira no Celin-UFPR: práticas docentes e experiências em sala de aula. Curitiba: UFPR, 2016. p. 321-338.

FARRELL, T. S. C. Critical incidents in ELT initial teacher training. ELT Journal, v.62, n.1, 3-10, 2008.

OLIVEIRA, M. Imigrantes haitianos no estado do Paraná em 2015. In: GEDIEL, J. A. P.; GODOY, G. (org.). Refúgio e Hospitalidade. Curitiba: Kairós, 2016. p. 249 - 275

PENNYCOOK, A. Critical applied linguistics. In: DAVIES, A.; ELDER, C. (ed.). The handbook of Applied Linguistics. Oxford: Blackwell, 2004.p. 1-24

PBMIH - Português Brasileiro para Migração Humanitária. Campanha Ser Migrante - Vozes e Culturas na UFPR - Por uma universidade aberta, plural e democrática. Curitiba: UFPR, 2018. vídeo (4:17 min). Disponível em: https://www.youtube.com/watch?v=L-1krZOll8M\&t=5s. Acesso em: 14 jul.2020.

PBMIH - Português Brasileiro para Migração Humanitária. Campanha Ser UFPR: - Vozes e Culturas na UFPR - Por uma universidade aberta, plural e democrática. Curitiba: UFPR, 2018 . vídeo (4:25 min). Disponível em: https://www.youtube.com/watch?v=mqehznZxu5Q. Acesso em: 14 jul.2020.

PBMIH - Português Brasileiro para Migração Humanitária. Materiais informativo

s para Migrantes. Curitiba: UFPR, 2020. Instagram: PBMIH @pbmih.ufpr. Disponível em: https://www.instagram.com/pbmih.ufpr/. Acesso em: 19 set.2020.

RESSONÂNCIAS UFPR. Curitiba: Revista Ressonâncias, v.1, n.1, 288p, mar. 2020. Disponível em: https://issuu.com/ressonancias .Acesso em: 21 junho. 2020.

RICHARDS, J. C.; FARRELL, T. S. C. Practice teaching: A reflective approach. Cambridge, UK: Cambridge University Press, 2008.

RUANO, B. P et al. Português brasileiro para migração humanitária (PBMIH): construindo um projeto de integração linguística, cultural e social. In: RUANO, B. P; SANTOS, J. P; SALTINI, L. (org.). Cursos de português como língua estrangeira no Celin-UFPR: práticas docentes e experiências em sala de aula. Curitiba: Editora UFPR, 2016. p. 291-316.

SOLEDADE, J; CUNHA, M....C. (org.). Projetos iniciais em português para falantes de outras línguas. Campinas: Pontes Editores, 2007. 
TOM UFPR. Andanças: Travessias da Migração e do Refúgio. TOM Cadernos de Ensaios, Curitiba, v.7, n.4, 224 p, sep. 2018. Disponível em: https://issuu.com/tom_ufpr/docs/tom7 .Acesso em: 16 abr. 2020.

WOODS, P. Critical events in teaching and Learning. New York: Routledge, 2012.

\section{()(1) $\ominus$}

Recebido em 27/08/2020. Aceito em 26/09/2020. 